\title{
VIVENDO EM CONSTANTE CONFLITO: O SIGNIFICADO DA PRÁTICA DOCENTE NO ENSINO MÉDIO DE ENFERMAGEM*
}

Lúcia Helena Pereira dos Santos**

Silvia Helena De Bortoli Cassiani***

SANTOS, L.H.P.dos; CASSIANI, S.H.de B. Vivendo em constante conflito: o significado da prática docente no ensino médio de enfermagem. Rev.latino-am.enfermagem, Ribeirão Preto, v. 8, n. 5, p. 58-64, outubro 2000.

O presente estudo, fruto de questionamentos e reflexões da autora, buscou compreender o significado que os enfermeiros, docentes do Ensino Médio de Enfermagem, atribuem à sua atividade profissional. Dada a natureza do problema, este estudo, de caráter qualitativo, utilizou como referencial metodológico a Teoria Fundamentada nos Dados (Grounded Theory). Os dados foram obtidos através de observações não-participantes e entrevistas semi-estruturadas, tendo como atores nove professores de três escolas localizadas no interior dos estados de Minas Gerais e São Paulo, que ministram os cursos de Auxiliar elou Técnico de Enfermagem. A análise dos dados possibilitou identificar o processo “VIVENDO EM CONSTANTE CONFLITO”, como o cerne da questão pesquisada, já que os professores manifestaram sentimentos e ações ambíguos em relação à sua prática profissional.

UNITERMOS: educação em enfermagem, docente de enfermagem

\section{INTRODUÇÃO}

No Brasil, os Atendentes de Enfermagem, ou seja, o pessoal sem qualificação atuando na Enfermagem, representam a maioria da mão de obra em exercício (CONSELHO REGIONAL DE ENFERMAGEM DE SÃO PAULO, 1995). Atualmente, o número desse pessoal perfaz um total de 140.287 trabalhadores que compõem a equipe de Enfermagem.

No que concerne ao pessoal qualificado, atualmente a Enfermagem apresenta o seguinte contingente: Enfermeiros - 68.828; Técnicos de Enfermagem - 60.667; Auxiliares de Enfermagem 265.779. Destaca-se que os Técnicos e Auxiliares de Enfermagem somam 326.446 trabalhadores, ou seja, representam $60 \%$ da força de trabalho em Enfermagem no Brasil (CONSELHO FEDERAL DE ENFERMAGEM, 1997).

Estudo de GASTALDO \& OSCAR (1991) aponta como principais fatores geradores da má distribuição de escolas destinadas à formação desses profissionais, os seguintes aspectos: a pouca importância dada à profissionalização de nível médio; a falta de um projeto nacional ou estadual de criação de escolas e o descomprometimento do Governo Federal com o ensino público e gratuito em todos os seus níveis.

CHIECO (1989) e FRIEDLANDER et al. (1992) apontam a problemática do corpo docente como um dos pontos mais críticos para a formação adequada do Técnico de Enfermagem, assim como do profissional de nível médio em geral. Dentre eles, destaca-se a ausência de preparação específica e carreira no magistério, o reduzido estímulo salarial, o despreparo, o desinteresse e a desatualização do professor. Esses últimos fatores são apontados como as principais críticas feitas ao curso pelos egressos.

Diante desse contexto, este estudo privilegiou a compreensão da realidade do professor do Ensino Médio de Enfermagem. MINAYO (1994) salienta que $a$ realidade social é o próprio dinamismo da vida individual e coletiva com toda a riqueza de significados dela transbordante. Enfatiza ainda que essa mesma realidade é mais rica que qualquer teoria, qualquer pensamento e qualquer discurso que possamos elaborar sobre ela.

Pelas razões aqui pontuadas, acredito que seja premente investigar sob o ponto de vista dos Enfermeirosdocentes do Ensino Médio de Enfermagem, o significado

\footnotetext{
* Artigo extraído da Dissertação de Mestrado apresentada ao Programa de Pós-Graduação em Enfermagem Fundamental da Escola de Enfermagem de Ribeirão Preto da Universidade de São Paulo

** Enfermeira, Professor do Curso Técnico em Enfermagem da Escola Técnica de Saúde da Universidade Federal de Uberlândia *** Enfermeira, Professor Doutor do Departamento de Enfermagem Geral e Especializada da Escola de Enfermagem de Ribeirão Preto da Universidade de São Paulo
} 
que atribuem à sua prática profissional, e é esse o propósito deste estudo.

\section{OBJETIVO DO ESTUDO}

Este estudo teve como objetivo compreender o significado que os Enfermeiros, docentes do Ensino Médio de Enfermagem, atribuem à sua prática profissional.

\section{PROCEDIMENTOS TEÓRICO-METODO- LÓGICOS}

Dentre os vários métodos de pesquisa qualitativa existentes, a opção foi pela "Grounded Theory" ou Teoria Fundamentada nos Dados. A opção deveu-se à intenção de realizar um estudo que privilegiasse os dados e a ação, e conseqüentemente, conduzisse ao âmago da questão pesquisada, vislumbrando-se assim, a compreensão do fenômeno.

Trata-se de um método originalmente desenvolvido por dois sociólogos: Barney Glaser e Anselm Strauss, cujo objetivo é a construção de uma teoria com potencial de iluminar a área sob estudo (STRAUSS \& CORBIN, 1990). Portanto, a Teoria Fundamentada nos Dados é uma forma de pesquisa de campo, que explora e descreve o fenômeno no ambiente em que ele se insere. A construção teórica, proveniente do estudo explica a ação no contexto social.

A Teoria Fundamentada nos Dados é de extrema importância para o estudo dos fenômenos em Enfermagem, já que é usada para explorar os processos sociais que se apresentam com as interações humanas, explorando a riqueza e a diversidade da experiência humana (STREUBERT \& CARPENTER, 1995).

Neste estudo foram utilizadas as técnicas de observação não-participante e entrevista semi-estruturada, enquanto estratégias de coleta de dados. Optei por observar e entrevistar Enfermeiros, docentes de três escolas: a primeira localizada em uma cidade do interior do estado de Minas Gerais e as outras duas no interior do estado de São Paulo.

A opção foi por selecionar escolas com características diferentes entre si, no que diz respeito à instituição mantenedora, aos cursos ministrados, Auxiliar e/ou Técnico em Enfermagem, e o número de alunos e turmas.

Contatos prévios foram estabelecidos com o diretor e/ou coordenador do curso, e posteriormente com o corpo docente, com a finalidade de informar-lhe sobre o estudo e obter autorização para a coleta de dados naquela instituição.

Para que fosse preservado o anonimato dos atores envolvidos, adotei um pseudônimo para cada um deles.

As observações não-participantes foram realizadas em diferentes momentos e locais. Estas constaram de observações de: professores em atividades com os alunos (aulas teóricas e estágios supervisionados); reuniões do corpo docente entre si e com a administração; conversas informais (na sala de professores, no cafezinho, no almoço, no hospital, durante a reunião e por telefone).

Foram realizadas 9 entrevistas com tempo médio de 30 minutos/cada, e a pergunta norteadora era: O que é ou o que significa para você ser docente do Ensino Médio de Enfermagem? Todas as entrevistas foram gravadas em fitas $\mathrm{k} 7$ e imediatamente após a sua realização, as fitas eram transcritas, e $\log$ o em seguida iniciava os procedimentos de codificação, ou seja, a análise dos dados.

\section{ANÁLISE E DISCUSSÃO DOS RESULTADOS}

"VIVENDO EM CONSTANTE CONFLITO" emerge como o fenômeno ou a categoria central, pois constitui-se no cerne do processo de integração entre as categorias, ou seja, todas giram em torno desta.

O fenômeno "VIVENDO EM CONSTANTE CONFLITO" representa a ambigüidade de sentimentos e ações, isto é, ora os sentimentos e ações manifestados pelo professor, em relação à sua prática profissional, são positivos, ora são negativos. Há manifestações mostrando que a prática docente é prazerosa, mas ao mesmo tempo desgastante.

As categorias e sub-categorias estão integradas ao fenômeno central, e apresentadas em termos de condições causais, contexto, estratégias de ação e/ou interação, condições intervenientes e conseqüências.

As categorias "TENDO INDEFINIÇÕES QUANTO À FORMAÇÃO E ATUAÇÃO DO FUTURO PROFISSIONAL" e "FAZENDO DE CONTA COM O ALUNO" determinam as causas que desencadeiam o fenômeno em questão, ou seja, "VIVENDO EM CONSTANTE CONFLITO".

"TENDO INDEFINIÇÕES QUANTO À FORMAÇÃO E ATUAÇÃO DO FUTURO PROFISSIONAL" refere-se à falta de diretriz, à falta de se delimitar o perfil do futuro profissional. Esta indefinição é mais evidente na formação do Técnico de Enfermagem, proveniente talvez, da própria indefinição da atuação deste profissional no mercado de trabalho. $\mathrm{O}$ próprio professor indaga: ... até onde vai o auxiliar... até onde vai o técnico? Será que a gente está formando o auxiliar, o técnico ou o micro-enfermeiro? O técnico é um desafio prá gente.... 
As sub-categorias que emergem desta categoria, e portanto, são também identificadas pelos professores como as condições causais do fenômeno "VIVENDO EM CONSTANTE CONFLITO" são: "Formando um micro-Enfermeiro?" e "Sentindo que desenvolve um trabalho isolado".

Já a categoria "FAZENDO DE CONTA COM O ALUNO" refere-se ao professor que rejeita o ensino de campo no hospital, preferindo permanecer na escola, no laboratório de técnicas básicas de Enfermagem. O laboratório de Enfermagem é um local indispensável para o ensino dos procedimentos básicos de Enfermagem. No entanto, algumas falas revelaram que há professores que preferem permanecer no laboratório com os alunos por um período maior do que o necessário para aprendizagem. O próprio professor afirma que, no laboratório, a relação estabelecida com o aluno é realmente de "faz-de-conta", pois no hospital, com o paciente, não resta dúvida que é uma situação muito diferente, e conseqüentemente a responsabilidade é muito maior.

O "fazer-de-conta" refere-se também ao esforço empreendido pelo professor, na tentativa de suprir a falta de material didático existente: ...sonda nasogástrica eles só imaginam, não passa, porque não tem boneco... sonda vesical só passa no homem, nós não temos os órgãos genitais da mulher...

Esta categoria diz respeito a situações bastante diferentes, porém ambas desencadeando o processo "VIVENDO EM CONSTANTE CONFLITO", já que as duas realidades apresentadas são preocupantes: a primeira, pela falta que o ensino prático faz ao aluno, e a segunda, pelo fato de adaptar, trabalhar e conformar-se com a falta de material didático apropriado para o ensino dos procedimentos básicos de Enfermagem.

O contexto onde ocorrem as interações e relações sociais, que geram os conflitos para o professor do Ensino Médio de Enfermagem, é representado pelas relações que mantém consigo mesmo, com a instituição na qual o professor encontra-se inserido, e com os alunos.

O contexto e as condições causais pertencentes ao fenômeno "VIVENDO EM CONSTANTE CONFLITO" estão fortemente imbricados, pois ambos relacionam-se às questões do próprio professor, à instituição e à relação professor-aluno.

As categorias relativas ao contexto são: "NÃO TENDO INFRA-ESTRUTURA FÍSICA E MATERIAL"; "TENDO QUE TER VÁRIOS OLHOS AO LIDAR COM O ALUNO" e "SENTINDO-SE FINANCEIRAMENTE".

A categoria "NÃO TENDO INFRAESTRUTURA FÍSICA E MATERIAL” refere-se à falta de condições físicas e materiais adequadas para o desempenho das atividades de ensino no espaço físico propriamente dito. O professor manifesta: ...o laboratório funciona também como sala ambiente de química, de física... o nosso laboratório é muito mal montado... o boneco é muito antigo, tem mais de 20 anos, ele está em péssimas condições, sem cabeça, sem olho... tinha uma biomédica dando Introdução a Enfermagem... nós temos um fisioterapeuta dando Pronto-Socorro... tem uma Técnica de Enfermagem dando aula no Técnico...

Através de avaliação da estrutura escolar dos Cursos Técnicos de Enfermagem do estado de São Paulo, NARCHI (1994) constatou deficiências referentes à escassez de material indispensável às aulas práticas de Enfermagem, ao insuficiente espaço físico destinado ao laboratório de Enfermagem e ao insuficiente material de apoio didático.

“TENDO QUE TER VÁRIOS OLHOS AO LIDAR COM O ALUNO" emerge retratando as dificuldades decorrentes da relação com os mais diferentes tipos de aluno. Os cursos diferem, no sentido de que alguns recebem alunos adolescentes, recém-saídos do $1^{\circ}$ grau, enquanto outros recebem alunos com uma faixa etária maior, adultos, especialmente Atendentes de Enfermagem, que estão em busca de qualificação e/ou habilitação profissional, e há ainda os cursos que recebem os dois tipos de alunos, trabalhando então com turmas mescladas de adolescentes e adultos.

Para o professor, é um conflito tanto lidar com o adolescente, pelas próprias características inerentes a essa idade, quanto lidar com o adulto, na maioria das vezes já atuando na área, e segundo o professor, já com os "vícios".

Em relação ao ensino prático, o professor comenta: ... a gente tem que ter vários olhos ao mesmo tempo para ver tudo o que está acontecendo....

Dessa forma, esta categoria divide-se em três subcategorias: Lidando com o aluno trabalhador; Lidando com o aluno adolescente; Tendo que trabalhar individualmente com o aluno e Sentindo grande responsabilidade com o ensino prático.

Sem dúvida alguma, todo esse contexto torna-se desfavorável ao trabalho do professor. Entretanto, a má remuneração é ainda um outro fator que interfere negativamente na situação, acentuando o processo "VIVENDO EM CONSTANTE CONFLITO".

"SENTINDO-SE DESVALORIZADO FINANCEIRAMENTE" constitui-se em outra situação contextual, significativa e conflitante no trabalho do professor, pois esta categoria diz respeito à questão salarial, à má remuneração percebida pelo profissional do ensino médio e, conseqüentemente, a sentir-se financeiramente prejudicado e desvalorizado profissionalmente.

Vale ressaltar que, infelizmente, esta não é uma queixa apenas do professor que atua no Ensino Médio de 
Enfermagem, mas também dos professores e dos Enfermeiros em geral, estejam eles inseridos na assistência ou na docência, em qualquer nível.

Todo esse contexto gera uma situação conflitante e de sobrecarga para o professor, pois com baixos salários, há a necessidade de buscar por um trabalho adicional.

Para NÓVOA (1995) o salário dos professores é considerado uma espécie de "gratificação", admitindo, portanto, a dupla atividade.

O estudo de MELLO (1988) revelou que a maior porcentagem de professores insatisfeitos, aproximadamente $83 \%$, é observada no que diz respeito à questão salarial. Para DEMO (1995) o professor é vítima de um sistema perverso, onde perpetuam condições indignas de trabalho, com remunerações indizíveis.

Este é pois o contexto que se apresenta, ou seja, o ambiente onde ocorrem os atos, as relações e interações que envolvem o professor do Ensino Médio de Enfermagem, bem como as condições em que estes ocorrem. Embora tenha delimitado algumas categorias para o contexto, entendo que a própria situação contextual constitui-se em uma condição causal para os conflitos manifestados pelo professor.

As estratégias de ação e/ou interação constituemse em formas de se responder ao fenômeno "VIVENDO EM CONSTANTE CONFLITO". As categorias que representam as estratégias de ação, pessoais e/ou profissionais são: "BUSCANDO APRIMORAR-SE NA RELAÇÃO COM O ALUNO" e "BUSCANDO O APRIMORAMENTO DE CONHECIMENTOS". Já as categorias que fazem parte das estratégias de ensino são: “IMPROVISANDO NO ENSINO" e "NIVELANDO O ALUNO POR BAIXO".

A categoria "BUSCANDO APRIMORAR-SE NA RELAÇÃO COM O ALUNO" diz respeito às tentativas de mudança que o professor acredita serem necessárias, enquanto pessoa e profissional, visando o seu crescimento, e ao mesmo tempo, um melhor relacionamento com os alunos.

Já a categoria "BUSCANDO O APRIMORAMENTO DE CONHECIMENTOS" emerge de uma necessidade expressa pelo professor: esse é o grande lance quando você dá aula... de um jeito ou de outro você volta a estudar... eu voltei a estudar....

As formas de atualização que o professor encontra e que são as sub-categorias identificadas na categoria "BUSCANDO O APRIMORAMENTO DE CONHECIMENTOS" são: "Participando de grupos de estudos e eventos" e "Buscando ser um professor menos tecnicista". Estas foram apontadas pelos professores como formas de se buscar a atualização profissional.

Por outro lado, há professores, cuja opção é por não voltar a estudar, não se aperfeiçoar, como mostra sua própria fala: ...eи estou trabalhando mesmo... fazendo o que eu tenho que fazer e tá bom... eu estou sem pique prá muita coisa....

A atualização profissional sistemática é definida por DEMO (1995) como decorrência natural do aprender a aprender e da moderna concepção de ciência como inovação em processo. Enfatiza ainda que a competência profissional traduz-se na capacidade de constante atualização, sendo que a falta desta gera a crescente obsolescência.

"IMPROVISANDO NO ENSINO" é outra estratégia de ação utilizada pelo professor. Na falta de infra-estrutura, o professor lança mão de recursos como a adaptação e a improvisação, tentando suprir a falta de material didático apropriado para o ensino e aprendizagem. Além de ser uma estratégia de ação utilizada, esta categoria também traduz-se em mais um momento difícil para o professor, fortalecendo o processo “VIVENDO EM CONSTANTE CONFLITO", já que ele próprio sente brigar consigo mesmo, pois tem consciência de que quanto mais for dando um jeitinho, ou quebrando o galho, mais as coisas não vão aparecendo.

A fala de um ator denota o quanto o professor tem que se virar, até mesmo comprar material didático numa "sex-shop: ...aqui a gente dança catira, a gente não dá aula... você tem que se virar... a gente vai quebrando o galho... não tem o boneco, como você vai dar aula de cateterismo vesical... o que aconteceu? Nós fomos na Sex-shop... compramos um pênis e nós damos aula com isso... a gente pega um travesseiro, enrola o lençol para fazer de perna, coloca o pênis no meio amarrado... a gente vai adaptando... aqui se não tiver criatividade e imaginação você não dá aula....

A improvisação é comum, não apenas em se tratando de Ensino Médio de Enfermagem, mas constituise em uma prática utilizada pelos professores, pelos Enfermeiros e pela Enfermagem em geral.

A categoria "NIVELANDO O ALUNO POR BAIXO" surge como uma estratégia de ação utilizada para trabalhar com um número grande (aproximadamente 40), e com os mais diferentes tipos de aluno. O professor admite nivelar todos os alunos por baixo, como se todos não tivessem nenhum conhecimento, ignorando-se dessa forma toda a experiência de vida acumulada e todo o conhecimento adquirido.

Evidentemente esta não é uma prática aceita quando se almeja uma educação conscientizadora e que não se reduz à mera aquisição de conhecimento. WERNECK (1992) salienta que ao se nivelar o aluno por baixo, está se desvalorizando muitas manifestações de saber.

As categorias que representam as condições 
intervenientes, ou seja, as condições que de alguma forma interferem nas estratégias de ação e interação no processo "VIVENDO EM CONSTANTE CONFLITO" são: "NÃO TENDO ESTÍMULOS PARA ATUALIZARSE" e "TENDO QUESTÕES FAMILIARES". O professor aponta aspectos de ordem pessoal, familiar e de trabalho que dificultam e/ou impedem suas ações, sendo, portanto, desencorajadora e desestimulante a situação.

A categoria "NÃO TENDO ESTÍMULOS

PARA ATUALIZAR-SE" refere-se à condição de não ter estímulos internos e externos para voltar a estudar, para buscar um aprimoramento profissional, ou seja, falta a vontade interna e o apoio e incentivo institucional.

Estar acomodado parece ter alguma relação com o tempo de exercício da profissão. O próprio professor admite que estar com o tempo de serviço próximo à aposentadoria, conseqüentemente com a idade mais avançada, faz com que ele opte por não buscar por um aperfeiçoamento profissional.

“TENDO QUESTÕES FAMILIARES" está relacionada com o cotidiano familiar e às dificuldades encontradas em conciliar as questões familiares ao desenvolvimento profissional. Tais questões muitas vezes impedem e/ou dificultam toda e qualquer atividade extratrabalho. O professor comenta: ... a minha vida particular me segurou um pouco, às vezes traz um pouquinho de arrependimento....

O professor encontra-se desprovido de estímulos para atualizar-se. De certa forma, sente-se preso às questões de ordem pessoal, familiar e de trabalho. Tais fatores funcionam como barreiras que impedem ou limitam o seu desenvolvimento profissional naquele momento.

As conseqüências do fenômeno "VIVENDO EM CONSTANTE CONFLITO" constituem-se nas expectativas das ações e/ou interações, ou seja, os resultados propriamente ditos. As categorias pertencentes às conseqüências são: "SENTINDO-SE ENTUSIASMADO E GRATIFICADO", "SENTINDO-SE UM SUB-PROFESSOR" e "SENTINDO-SE DESGASTADO".
A categoria
"SENTINDO-SE

ENTUSIASMADO E GRATIFICADO” emerge dos sentimentos positivos manifestados pelo professor, como os de sentir-se entusiasmado e extremamente gratificado pelo trabalho que realiza, uma vez que sente a importância de trabalhar com o aluno que brevemente estará atuando no hospital.

Para o professor, a formatura dos alunos é um momento extremamente gratificante e de muita alegria, pois considera que aí está o resultado do seu trabalho, e afirma: ... a cada ano que você vê uma turma formando, você vê que é um pedacinho de você que está ali, um pouquinho do que você passou... um pouquinho de amor à profissão....

A categoria "SENTINDO-SE UM SUBPROFESSOR" aponta os sentimentos manifestados pelo professor, como inferioridade, discriminação, desvalorização e falta de reconhecimento pelo trabalho realizado. O professor afirma: nós, do Ensino Médio de Enfermagem, não somos muito conhecidos. Contudo, os professores acreditam que esses sentimentos são manifestados pelos Enfermeiros em geral, já que a Enfermagem está muito desvalorizada, não só financeiramente.

O professor sente-se desvalorizado até mesmo pelos próprios colegas Enfermeiros, especialmente aqueles que se encontram inseridos na assistência, na área hospitalar, que muitas vezes imaginam e até afirmam que o trabalho do professor é muito tranqüilo.

"SENTINDO-SE DESGASTADO" diz respeito ao desgaste proporcionado pela profissão. A fala dos professores indica que o cansaço e o desânimo manifestados, estão diretamente relacionados com a insatisfação em relação ao curso e com o tempo de exercício da profissão, e por isso acreditam que deveriam aposentar-se com 15 anos, já que não se tem mais o "pico de ação" que havia até os 10 anos de profissão.

O desânimo também é manifestado no início do ano, quando o professor até questiona: será que eu vou agüentar passar por tudo isso de novo? Ele próprio afirma ter um estresse maior no início do ano, mas depois com o decorrer do tempo, à medida que caminha, afirma achar "mais fácil e mais tranqüilo".

Vale ressaltar que o desânimo não é uma queixa apenas dos professores, mas dos Enfermeiros em geral, pois ele próprio afirma viver um momento depressivo de sua carreira, sendo pessimista e não tendo esperança de melhora e de mudança, ao contrário, sente-se desanimado por julgar-se extremamente desvalorizado como profissional.

Diante da situação de desvalorização que vivenciam, tornam-se visíveis a desmotivação pessoal, a insatisfação profissional e uma espécie de "autodepreciação" em relação à prática docente. Tal prática situa-se num processo histórico em que as mudanças sociais provocaram profundas transformações, traduzindo-se portanto, na intersecção de diferentes contextos (NÓVOA, 1995).

Para mim foi interessante observar os sentimentos manifestados pelo professor: dois extremos se fazem presentes, acentuando os conflitos vivenciados.

O fenômeno "VIVENDO EM CONSTANTE CONFLITO" revela as dificuldades e limitações enfrentadas pelo professor, assim como revela também a prática docente no Ensino Médio de Enfermagem como uma atividade prazerosa, apesar dos dissabores. 


\section{CONSIDERAÇÕES FINAIS}

Este estudo mostrou-me que a prática educativa do professor do Ensino Médio de Enfermagem constituise em uma atividade extremamente complexa, resultado da interação de múltiplos fatores e condições, tais quais foram apresentadas.

A realidade do contexto de trabalho do professor está diretamente relacionada ao meio socialmente organizado em que desenvolve seu trabalho, onde se manifestam, constantemente, abundantes conflitos. Para LINHARES (1993), os conflitos vivenciados pelo professor são conflitos de classe que se interpenetram com os conflitos de identidade pessoal e profissional.

Em se tratando da profissão docente, SACRISTÁN (1995) afirma que esta é socialmente partilhada, o que explica a sua dimensão conflituosa numa sociedade complexa na qual os significados divergem entre grupos sociais, econômicos e culturais. Para este autor, o professor é um administrador de dilemas, pois os dilemas representam os pontos de conflito em que se articulam pensamento e ação.

A situação ora detectada, explica e até mesmo justifica o processo "VIVENDO EM CONSTANTE CONFLITO" que se revelou entre os professores participantes deste estudo.

Mais do que provocar reflexões e realizar propostas, esta investigação pretendeu compreender os sentimentos, as ações, as dificuldades, enfim, as mais diferentes manifestações dos professores em relação à sua prática no Ensino Médio de Enfermagem.

Ao final deste estudo, posso perceber que a formação do profissional de nível médio de Enfermagem não deve ser limitada, despida de compreensão, de análise e de crítica, determinada simplesmente pelo mero "saber fazer". Acredito ser essencial uma formação básica sólida e renovada, capaz de permitir ao aluno refazer-se, repensar-se e intervir na realidade. E isto está nas mãos do professor. É fundamental pois, que este desperte no aluno a capacidade de saber pensar e questionar de forma crítica e criativa.

Para se alcançar tal meta, creio que torna-se premente, professores não apenas técnicos, mas criadores, capazes de "aprender a aprender". Daí a necessidade de preparo específico para o exercício de tal atividade, que não é simples e reveste-se de importância não apenas para a Enfermagem, mas para a sociedade em geral.

\section{LIVING IN CONSTANT CONFLICT: THE MEANING OF TEACHING IN SECONDARY NURSING COURSES}

This study was a result of the author's inquiries and reflections, aiming at understanding the meaning that nurses teaching in secondary Nursing courses give to their job. Considering the nature of the problem, this qualitative study used the Grounded Theory as its methodological framework. Data were collected by means of both observation and semi-structured interviews with nine teachers from three schools located in areas of the states of Minas Gerais and São Paulo that offer courses to technicians and/or auxiliary nurses. Data analysis enabled the identification of the "LIVING IN CONSTANT CONFLICT" process as the central theme, especially if we consider that the teachers showed ambiguous feelings and actions regarding their professional practice.

KEY WORDS: nursing education, faculty nursing

\section{VIVIENDO EN CONSTANTE CONFLICTO: EL SIGNIFICADO DE LA PRÁCTICA DOCENTE EN LA ENSEÑANZA MEDIA DE ENFERMERÍA}

El presente estudio, fruto de preguntas y reflexiones de la autora, buscó comprender el significado que los enfermeros, docentes de Enseñanza Media de Enfermería, atribuyen a su actividad profesional. Debido a la naturaleza del problema, este estudio de carácter cualitativo, utilizó como referencia metodológica la Teoría Fundamentada en los Datos (Grounded Theory). Los datos han sido obtenidos a través de observaciones indirectas y entrevistas semiestructuradas, teniendo como actores nueve profesores de tres escuelas ubicadas en el interior de los estados de Minas Gerais y São Paulo, que dan los cursos de Auxiliar y/ o Técnico de Enfermería. El análisis de los datos há posibilitado identificar el proceso "VIVIENDO EN CONSTANTE CONFLICTO” como la parte más importante de la temática investigada, ya que los profesores han manifestado sentimientos y acciones ambíguas en relación con su práctica profesional. 


\section{REFERÊNCIAS BIBLIOGRÁFICAS}

01. CHIECO, N.W. O descompasso entre as mudanças tecnológicas e os currículos adotados nas escolas técnicas. Tecnologia Educacional, Rio de Janeiro, v. 18, n. 87/88, p. 9-17, 1989.

02. CONSELHO FEDERAL DE ENFERMAGEM. População de profissionais cadastrados até 30/ 04/97. Rio de Janeiro: COFEN, 1997.

03. CONSELHO REGIONAL DE ENFERMAGEM DE SÃO PAULO. Informativo COREN - SP. São Paulo: COREN, 1995.

04. DEMO, P. Desafios modernos da Educação. 3. ed. Petrópolis: Vozes, 1995. 270p.

05. FRIEDLANDER, M.R.; SECAF, V.; MATSUI, T. O ensino de enfermagem em nível médio./ Apresentado ao 11. Congresso da Associação Médica Brasileira, São Paulo, 1992/.

06. GASTALDO, D.M.; OSCAR, M.F.A. A realidade da formação do auxiliar e do técnico de enfermagem do RS e a atuação da comissão de educação da Associação Brasileira de Enfermagem - Seção RS. Revista Gaúcha de Enfermagem, Porto Alegre, v. 12, n. 1, p. 46-52, 1991.

07. LINHARES, C.F.S. Trabalhadores sem trabalho e seus professores: um desafio para a formação docente. In: ALVES, N. (org.). Formação de professores: pensar e fazer. São Paulo: Cortez, 1993. Cap. 1, p. 9-36.
08. MELlO, G.N. Magistério de 10 grau: da competência técnica ao compromisso político. 9. ed. São Paulo: Cortez/Autores Associados, 1988. $151 \mathrm{p}$.

09. MINAYO, M.C.S. Ciência, técnica e arte: o desafio da Pesquisa Social. In: MINAYO, M.C.S. (Org.). Pesquisa social: teoria, método e criatividade. 5. ed. Petrópolis: Vozes, 1994.

10. NARCHI, N.Z. Cursos técnicos de enfermagem: avaliação da estrutura escolar, da operacionalização curricular e da disciplina enfermagem materno-infantil. São Paulo, 1994. 170p. Dissertação (Mestrado) - Escola de Enfermagem, Universidade de São Paulo.

11. NÓVOA, A. O passado e o presente dos professores. In: NÓVOA, A. (Org.) Profissão professor. Portugal: Porto Editora, 1995. Cap. 1, p. 13-34.

12. SACRISTÁN, J.G. Consciência e acção sobre a prática como libertação profissional dos professores. In: NÓVOA, A. (Org.). Profissão professor. Portugal: Porto Editora, 1995. Cap. 3, p. 63-92.

13. STRAUSS, A.; CORBIN, J. Basics of qualitative research. Thousand Oaks: Sage Publications, 1990.

14. STREUBERT, H.J.; CARPENTER, D.R. Qualitative research in nursing. Philadelphia: J.B. Lippincott, 1995. Cap. 7, p. 145-161: Grounded theory research approach.

15. WERNECK, H. Se você finge que ensina, eu finjo que aprendo. 11. ed. Petrópolis: Vozes, 1992. 